\title{
Chapter 28 \\ Consideration of Treatment and Disposal of Secondary Wastes Generated from Treatment of Contaminated Water
}

\author{
Hiromi Tanabe and Kuniyoshi Hoshino
}

\begin{abstract}
The earthquake and tsunami on March 11, 2011, caused severe accidents at the several Fukushima Daiichi Nuclear Power Units, and a significant volume of highly contaminated water was generated from the accident. Several methods have been applied to decontaminate the water, including systems from AREVA S.A. and Kurion, Inc., in addition to the SARRY (Simplified Active Water Retrieval and Recovery System) and ALPS [Advanced Liquid Processing System; incorporated in the MRRS (Multi Radionuclide Removal System)] systems from Toshiba Corporation. After the decontamination treatments using these systems, various kinds of sludge and spent adsorbents were generated as secondary wastes. These wastes are now tentatively stored at the site, but further treatment shall be applied to produce appropriate waste forms for interim storage and final disposal in a repository.

Waste management - the treatment, storage, transportation, and disposal of these wastes - is believed to require several decades. The authors examined how to manage these wastes in consideration of the large volume of waste, the variety of waste types, and the long period required to carry out their treatment and disposal in a safe and efficient manner. The requirements for an inventory list and online waste management system; a development strategy for waste treatment, storage, transport, and disposal; formation of an R\&D implementation and evaluation team; and long-term knowledge management are discussed in this chapter.
\end{abstract}

Keywords Contaminated water - Disposal - Fukushima Daiichi Nuclear Power Units $\bullet$ Inventory $\bullet$ Secondary waste $\bullet$ Treatment

H. Tanabe $(\bowtie) \cdot K$. Hoshino

Radioactive Waste Management Funding and Research Center, 1-15-7,

Tsukishima, Chuo-ku, Tokyo, Japan

e-mail: tanabe.hiromi@rwmc.or.jp 


\subsection{Introduction}

A significant volume of highly contaminated water was generated from the accidents at the Fukushima Daiichi Nuclear Power Units. Several methods have been applied to decontaminate the water. After decontamination treatments using several systems developed by AREVA, Kurion, and Toshiba, various kinds of sludge and spent adsorbents were generated as secondary wastes. These wastes are now tentatively stored at the site, but further treatment shall be applied to produce appropriate waste forms for interim storage and final disposal in a repository. Management of these wastes is believed to take several decades. The authors examined how to manage these wastes in consideration of the large volume of waste, the variety of waste types, and the long period to carry out the treatment and disposal in a safe and efficient manner. The issues identified are discussed in the following sections.

\subsection{Requirements for an Inventory List and Online Waste Management System}

A fundamental issue is to establish a raw waste inventory list with information on various characteristics, including chemical and physical form and radionuclide inventory (Table 28.1). This is the first step for pursuing further examination of treatment and disposal of these wastes. However, it is very difficult to establish a

Table 28.1 Important characteristics of radioactive waste that may be used as parameters for waste classification [1]

\begin{tabular}{l|l}
\hline Origin & Chemical properties: \\
\hline Criticality & Chemical composition \\
\hline Radiological properties: & Solubility and chelating agents \\
\hline Half-lives of radionuclides & Potential chemical hazard \\
\hline Heat generation & Corrosion resistance/corrosiveness \\
\hline Intensity of penetrating radiation & Organic content \\
\hline Activity concentration of radionuclides & Combustibility and flammability \\
\hline Surface contamination & Chemical reactivity and swelling potential \\
\hline Dose factors of relevant radionuclides & Gas generation \\
\hline Decay products & Sorption of radionuclides \\
\hline Physical properties: & Biological properties: \\
\hline Physical state (solid, liquid, or gaseous) & Potential biological hazards \\
\hline Size and weight & Bio-accumulation \\
\hline Compactibility & Other factors: \\
\hline Dispersibility & Volume \\
\hline Volatility & Amount arising per unit of time \\
\hline Miscibility & Physical distribution \\
\hline Free liquid content & \\
\hline
\end{tabular}


complete list from the beginning because the volume of waste and variety of waste types is large and certain radionuclides contained in the wastes are difficult to identify and measure. Therefore, stepwise development and evaluation are important. A management system of the waste inventory should be established, and new waste information obtained by several intensive waste characterization projects should be added to the management system, where the information will be shared among concerned organizations.

The management system should include information about treatment method and source term characteristics, including waste form, volume, surface dose rate, ID number, and location of waste package, which are collected when raw wastes are treated. This system should be maintained and used until final disposal of the wastes. When all wastes are disposed of in a designated disposal facility, the inventory list will be used as the waste records of the disposal facility.

\subsection{Development Strategy of Waste Treatment, Storage, Transport, and Disposal Technologies}

The authors proposed a work flow for selecting a waste management technology [2] (as shown in Fig. 28.1). Establishment of the development criteria for each technology is a fundamental issue and the first step of the development.

For treatment technology, it is important to have a simple system that can be applied to a variety of wastes, and which has a volume reduction factor and is economical. In addition, the system must minimize secondary waste and address the difficulty of residual research and development (R\&D) to commercialize the technology. Regarding the stability of waste forms produced by any treatment technology, a low leaching rate is required, especially for waste containing long-lived radionuclides over a certain amount. Easy identification and measurement of the radionuclides in the waste by the treatment process would also be considered an advantage.

Storage technology has many options that are either in operation or under R\&D in different countries. The storage cost is an important index to use when selecting an option. If a waste generates a large quantity of heat as a result of containing a large amount of beta- and gamma-emitting nuclides such as Cs-137, the waste storage period should be considered before final disposal to reduce heat generation. If the waste has greater heat generation in disposal, the waste emplacement area must be increased to reduce the temperature of the surrounding engineered barriers or rock to less than the allowable temperature. As a consequence, disposal cost will increase. The storage period and disposal cost have a strong mutual relationship. If the storage period must be increased by more than a few hundred years to reduce heat generation for disposal, certain radionuclides such as Cs-137, whose half-life is less than several decades, would have undergone significant decay by time of disposal, which also raises the possibility of lowering the waste classification level for disposal. 


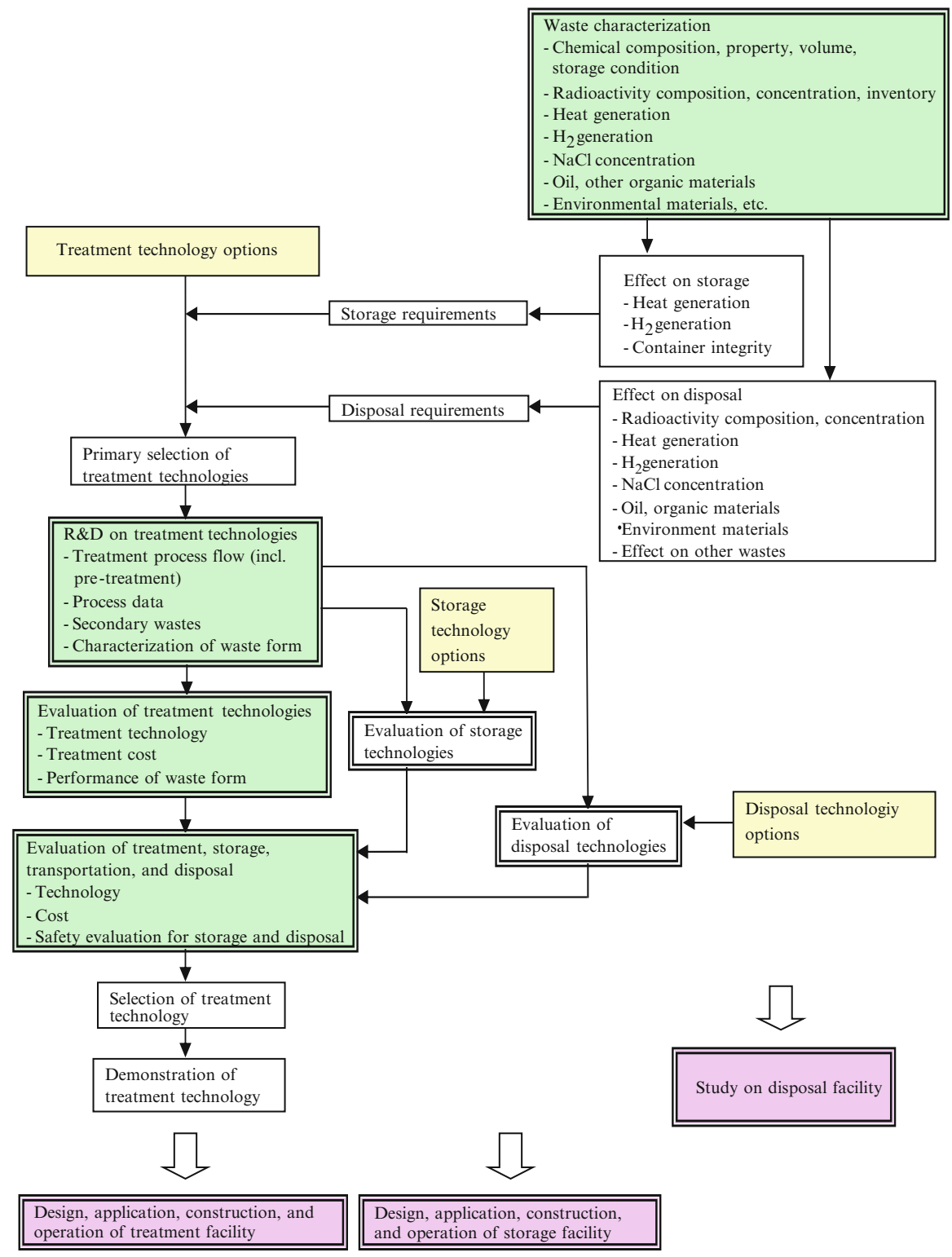

Fig. 28.1 Flow chart for selection of waste management technology [2]

Disposal technology also has many options that are either in operation or under $\mathrm{R} \& \mathrm{D}$ in different countries. The disposal cost depends on the design of the disposal facility, the composition of the engineered barriers, and the depth of the disposal facility, which are strongly dependent on the characteristics of the radionuclides in the waste. 
Table 28.2 Items for the management database of treatment technology options

\begin{tabular}{l}
\hline I.D. No. \\
\hline Name of technology \\
\hline Description of technology \\
\hline Applicability to various wastes \\
\hline Process flow diagram \\
\hline Description of process flow diagram \\
\hline Treatment conditions, including temperature, pressure, conditions, material \\
balance, radionuclide balance, and decontamination factor (DF) \\
\hline Chemical reagents and utilities \\
\hline Volume reduction ratio of waste \\
\hline Characteristics of waste form, including configuration, uniaxial compression \\
strength, vacant volume ratio, apparent density, leaching rate of radionuclides, \\
and leaching rate of chemical components \\
\hline Content and status of NaCl \\
\hline Status of technology; commercialization, development, fundamental research \\
\hline Technical issues (R\&D for commercialization) \\
\hline Standards to be applied \\
\hline References
\end{tabular}

Technology options for treatment, storage, transportation, and disposal have been proposed by domestic and international organizations. These options should be integrated and managed in a database of technology options. R\&D results should also be added in the database as soon as possible. To manage the technology options, a database should be prepared and used to share information among the related organizations. The authors proposed a set of items to be managed in the database of treatment technology options (Table 28.2).

When an appropriate technology is being selected from several options, it is important to evaluate each technology option and compare them. At the end, it is also important to evaluate the combination of technologies from treatment to disposal to make the final selection of an appropriate set of these technologies and to establish a total system for specific wastes. The authors propose a set of indexes for evaluation of the combination of waste management technologies (Table 28.3). Evaluation of the total system should include the long-term safety of disposal because this is the most important issue and goal of waste management.

\subsection{Formation of an R\&D Implementation and Evaluation Team}

The development of a waste inventory database and waste treatment technology and the evaluation of the feasibility of each technology and the total system of waste management requires a team composed of system engineers, researchers, 
Table 28.3 Evaluation indexes for combination of waste management technologies

\begin{tabular}{|c|c|c|}
\hline a. Treatment & b. Waste form & c. Storage \\
\hline $\begin{array}{l}\text {-Applicability to various } \\
\text { wastes }\end{array}$ & $\begin{array}{l}\text {-Waste classification for trans- } \\
\text { portation and disposal }\end{array}$ & -Storage method \\
\hline -Components & -Uniaxial compaction strength & $\begin{array}{l}-\mathrm{R} \& \mathrm{D} \text { for } \\
\text { commercialization }\end{array}$ \\
\hline $\begin{array}{l}\text {-Chemical reagent and } \\
\text { utilities }\end{array}$ & -Density & -Storage cost \\
\hline $\begin{array}{l}\text {-Measures to protect against } \\
\mathrm{NaCl} \text {-induced corrosion }\end{array}$ & -Vacant volume ratio & \\
\hline $\begin{array}{l}\text {-Material and radionuclide } \\
\text { balances }\end{array}$ & -Leaching rate of radionuclides & \\
\hline $\begin{array}{l}-\mathrm{R} \& \mathrm{D} \text { for } \\
\text { commercialization }\end{array}$ & $\begin{array}{l}\text {-Leaching rate of chemical } \\
\text { components }\end{array}$ & \\
\hline \multirow[t]{3}{*}{-Treatment cost } & $\begin{array}{l}\text {-Hydrogen generation rate and } \\
\text { measures to manage hydrogen }\end{array}$ & \\
\hline & -Temperature resistance & \\
\hline & -Radiation resistance & \\
\hline d. Transportation & e. Disposal & f. Evaluation of total system \\
\hline -Transportation container & $\begin{array}{l}\text {-Disposal method (design, } \\
\text { engineered barriers, depth) }\end{array}$ & $\begin{array}{l}-\mathrm{R} \& \mathrm{D} \text { for } \\
\text { commercialization }\end{array}$ \\
\hline \multirow[t]{2}{*}{-Transportation cost } & $-\mathrm{R} \& \mathrm{D}$ for commercialization & $\begin{array}{l}\text {-Treatment, storage, trans- } \\
\text { portation, and disposal cost }\end{array}$ \\
\hline & -Disposal cost & $\begin{array}{l}\text {-Long-term safety of } \\
\text { disposal }\end{array}$ \\
\hline
\end{tabular}

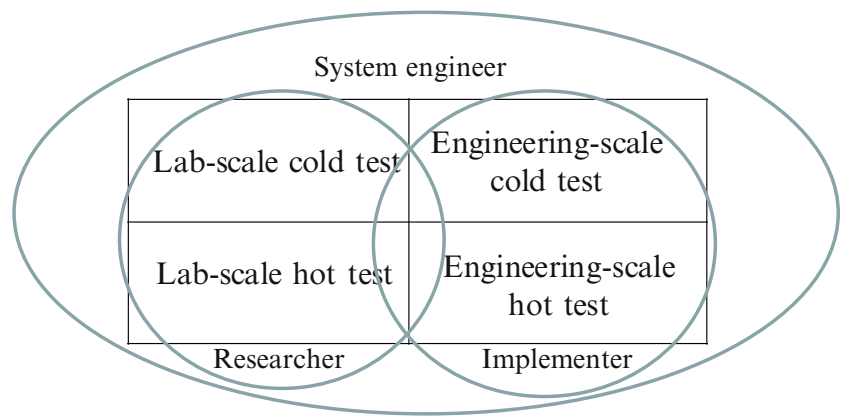

Fig. 28.2 Research and development $(R \& D)$ implementation and evaluation team

and implementers from the start of $R \& D$. The authors propose an $R \& D$ implementation and evaluation team (Fig. 28.2). The role of each member is as follows: researchers conduct laboratory-scale cold and hot tests for collecting basic information on waste inventory and treatment technology, implementers carry out engineering-scale cold and hot tests for commercializing the technology, and system engineers carry out the system design and cost evaluation of 
the technology to evaluate the feasibility of the technology. The members of the team should work together on R\&D and to check whether the data obtained are sufficient for all members. As a result of this collaboration, it is expected that sufficient data will be obtained to pursue the next phase of testing and to transfer the technical knowledge smoothly to other members. Because the engineeringscale test will be conducted by the implementers, education and training of future operators will be also performed. The team should also evaluate the storage, transportation, and disposal technology. For this purpose, system engineers who perform these evaluations should be involved.

\subsection{Requirements for Long-Term Knowledge Management}

As already stated, when a nuclear accident occurs there is a much larger volume of wastes and greater variety of waste types than the conventional wastes generated from the usual operation and planned decommissioning of a nuclear power unit. The wastes from a nuclear accident also contain a wider range of concentrations for the various radionuclides. Consequently, it will take a long period to characterize the wastes and to carry out the R\&D and evaluation of treatment and disposal technology. It is also expected that the actual treatment and disposal of the wastes will not take place until after more than a few decades. In consideration of this waste management period, long-term knowledge management is needed. The authors propose the formation of an $\mathrm{R} \& \mathrm{D}$ implementation and evaluation team that will manage and retain technical knowledge. The team should involve younger staff members, and education and training of the next generation of staff should be performed by on-the-job training (OJT).

\subsection{Conclusion}

A significant volume of highly contaminated water was generated from the accidents at the Fukushima Daiichi Nuclear Power Units. Several methods have been applied to decontaminate the radioactivity of the water, and these methods have generated various kinds of sludge and spent adsorbents as secondary wastes. Because long-term waste management is needed, the authors examined a broad range of issues concerning how to manage these wastes in a safe and efficient manner. The requirements for an inventory list and online waste management system; a development strategy for waste treatment, storage, transport, and disposal technology; formation of an R\&D implementation and evaluation team; and longterm knowledge management are proposed. 
Open Access This chapter is distributed under the terms of the Creative Commons Attribution Noncommercial License, which permits any noncommercial use, distribution, and reproduction in any medium, provided the original author(s) and source are credited.

\section{References}

1. International Atomic Energy Agency (2009) Classification of radioactive waste. IAEA Safety Standards Series No. GSG-1. IAEA, Vienna

2. Tanabe H (2013) Consideration on treatment and disposal of secondary wastes generated from treatment of contaminated water, B37. In: Proceedings of the 2013 annual meeting of Atomic Energy Society of Japan, Tokyo 